\title{
Anemia of Chronic Diseases (ACD)
}

\section{Bassam Abdul Rasool Hassan*}

Clinical pharmacy discipline, school of pharmaceutical sciences, University of Sains Malaysia, 11800, Minden, Penang, Malaysia

\section{Introduction of Anemia}

This is a condition characterized by lack of blood or in other word a reduction of total quantity of erythrocyte (red blood cells, RBC) or hemoglobin in the circulation which are necessary for normal function. This is caused by the inability of the bone marrow to replace the erythrocyte lost. The normal level of RBC for the male is $5.4 \times 10^{6} \mathrm{cell} / \mu \mathrm{l}$ and for female is $4.8 \times 10^{6} \mathrm{cell} / \mu \mathrm{l}$ [1-4].

It is considered as one of the most frequent hematological demonstration of malignant diseases, which will lead to momentous impairment in every tissues and organs of cancer patients and put them under serious stress. This major problem may arise because of the underlining diseases (i.e., cancer diseases) or radiotherapy or chemotherapy treatment received. This condition is characterized by lower hemoglobin $(\mathrm{Hb})$ level or inadequate circulating $\mathrm{RBC}$ or when the amount of iron absorbed each day is lower than the requirement $[5,6]$.

\section{Anemia of Chronic Diseases (ACD)}

This is the type of anemia mostly associated with infection, inflammation and cancer. It is characterized by hypoferremia, hyperferitinemia, reduction in transferin concentration and increases in iron stores. These are also the main factors or parameters to distinguish anemia of chronic diseases from that of iron deficiency anemia which showed the opposite characteristics. Most of the studies showed that $10 \%-40 \%$ of cancer patients also suffered from ACD. Cancer disease itself is considered as one of the leading causes of $\mathrm{ACD}$ and is related with the progression of cancer disease. There are several mechanisms by which ACD are caused such as bone marrow metastasis leading to myelosuppression or cytokines production like interlukine-1, interlukine-6, tumor necrosis factor (TNF- $\alpha$ ) and interferon (INF- $\gamma$ ) which will either inhibit erythropoietin (EPO) synthesis by the kidney (i.e., inhibit erythropoiesis) or inhibit EPO action on erythroid precursors leading to retention of iron in the reticuloendothelial system, gastrointestinal tract and hepatocytes or cytokine mediated failure of erythropoiesis. Several studies had proven that there are several cytokines in case of solid cancer diseases interfering with EPO synthesis. Other mechanisms includes bleeding, hemodilution, hypersplenism, hemophagocytosis and autoimmune. It is very important to note that ACD occurrence with cancer diseases is usually associated with advanced stages of solid cancer. Furthermore chemotherapy and radiotherapy both play a major role in the onset and severity of anemia since both of these two factors lead to bone marrow suppression and reduce EPO produced from the kidneys. Chemotherapy may double the incidence of anemia among cancer patients. Mainly anemia incidence and severity in cancer patients depend on the type of cancer as well as on the type and intensity of chemotherapy. However, anemia seems to be more common among patients with hematological cancer such as in multiple myeloma where $70 \%$ of the patients suffered from anemia $[1-4,7,8]$.

\section{Causes of Anemia of Chronic Diseases (ACD)}

Anemia remain as one of the serious and frequent problem of cancer mainly cancer of the gastrointestinal, liver, head, neck, ovarian and cervix. This is mainly caused by cytokine including interlukine- 1 , interlukine- 6 , interferon- $\gamma$ and tumor necrosis factor- $\alpha$ produced by these cancer diseases. These cytokines caused impairment of erythropoietin (EPO) synthesis, reduce erythrocytes life span and prevent normal iron utilization. Other direct effect of tumor that cause anemia is bone marrow replacement which is associated with inhibition of the body ability for the production of RBC. This condition of bone marrow suppression is associated with specific types of cancers like breast, prostate, myeloma, lymphoma and acute leukemia. Also bone marrow suppression is mainly caused by chemotherapy and radiotherapy which are the main treatment for cancer. Mainly in cancer patients the major risk factors responsible for incidence and severity of anemia are the form of cancer as well as type and dose of chemotherapy administered to the cancer patients $[1-4,7,9]$.

\section{Conclusion}

Therefore it is an obligate and/or recommended subject for the ongoing on preclinical studies to focus on the incidence of anemia among cancer patients.

\section{References}

1. Haut A (2007) Anaemia in Encyclopaedia of Science and Technology, Editors Weil J, Blumel D, Tylor R, Geller E, McGraw-Hill, New York, USA, 11-20.

2. Blaser $L$ (2001) Anaemia. The Gale Encyclopaedia of Science. Mcgrath KA, Lachford SB, Farmington Hills, Gale Group, USA.

3. Haggerty M (1999) Anaemia. The Gale Encyclopaedia of Medicine. Olendor D, Jeryan C, Boyaden K Farmington Hills, Gale Research, an International Thomson Company, USA.

4. Brown T, Olde TG (2005) Anemia. The Gale Encyclopedia of Cancer 2. Longe $\mathrm{JL}$, Detroit Gale Group, USA.

5. Pohl G, Ludwig H (2005) Positive effects of correction of anaemia in malignan diseases. Anaemia of Chronic Disease. Weiss G, Gordeuk VR, Hershko C Taylor \& Francis, New York, USA, 489-557.

6. Weiss G, Gordeuk VR, Hershko C (2005) Anaemia of Chronic Disease. Taylor \& Francis Group, New York, USA, 381-395.

7. Weiss G, Gordeuk VR, Hershko C (2005) Anaemia of Chronic Disease. Taylor \& Francis Group, New York, USA, 145-200.

8. Weiss G, Gordeuk VR, Hershko C (2005) Anaemia of Chronic Disease. Taylor \& Francis Group, New York, USA, 593-605.

9. Gordon MS (2002) Managing Anemia in the Cancer Patient: Old Problems Future Solutions. Oncologist 7: 331-341.
*Corresponding author: Bassam Abdul Rasool Hassan, Clinical pharmacy discipline, school of pharmaceutical sciences, University of Sains Malaysia, 11800, Minden, Penang, Malaysia, Tel: +60164230950; E-mail: bassamsunny@yahoo.com

Received November 13, 2013; Accepted November 15, 2013; Published November 18, 2013

Citation: Hassan BAR (2013) Anemia of Chronic Diseases (ACD). Nat Prod Chem Res 2:e104. doi:10.4172/2329-6836.1000e104

Copyright: ( 2013 Hassan BAR. This is an open-access article distributed under the terms of the Creative Commons Attribution License, which permits unrestricted use, distribution, and reproduction in any medium, provided the original author and source are credited. 